\title{
PROTANOPIA: AN ALTERNATIVE READING EXPERIENCE OF A DIGITAL COMIC
}

\author{
Chanya Hetayothin
}

King Mongkut's Institute of Technology Ladkrabang, Thailand

\begin{abstract}
Screen-based reading behavior is now prevalent in society. Comic artists switch media from traditional to digital - in order to allow for changing reading behavior, as well as to access more readers. Digital platforms range from a static computer screen to mobile devices such as phones, as well as tablets. This article aimed to explore the technological innovation of digital comics and the future of comic production. It discussed the following digital comic developed for mobile devices: Protanopia by Bergs (2017). The article explored how this digital comic offers a unique reading experience to its readers. The study analyzed personal experiences of reading the digital comic, literature reviews, as well as interviews with the comic artists. The findings were: (1) the comic offers images in a three-dimensional space and allows their readers to control the camera angle while reading by tilting the mobile device. This image-viewing control grants the readers an unconventional reading experience; (2) The comic artist uses an integrated technology using Unity and Alias Maya software to deliver a three-dimensional objects and space. The 2D look is later created from a drawn-over-3D image technique. This reveals that despite the software complication, hand-drawing is still a crucial stage. The study affirmed that the traditional way of visualization in comic making has not disappeared but adapted to the digital transformation. This paper provides observation on media changes in comics, as well as a direction for future comic production.
\end{abstract}

Keywords: digital comic production, protanopia

\section{Introduction}

Since computers were introduced as a tool to assist comic production, digital comics have showed signs of coming into existence. According to Jensen (2018), the first comic generated by computer - Shatter - was published by First Comics in 1985. Notwithstanding, the comic was in a print format. A ubiquity of computers and the rise of mobile devices such as smartphones increase screen-based reading number in the past years. This is affirmed by Ziming Liu's research in 2005 which implies that reading behavior has been changed over past ten years from paper-based to screen-based reading. Now mobile devices, such as kindle and iPad, serve as alternative screen-based reading tools.

Comic publishers adapt to the changing reading behavior by making comics, graphic novels and manga in digital formats. Chris Coller, manager of the comic shop Earth 2, acknowledged that digital comics have grown regarding their easy access and simple storage capability (Miranda, 2016). In Japan, screen-based readers increased so much that "sales of digital manga books excluding magazines jumped 27 percent to 146 billion yen in 2016 from the year before while sales of paper manga saw a record year-on-year decline of 7.4 percent to 194.7 billion" (Nagata, 2017). In the west, Marvel Comics launched its on-line comic site called Marvel Digital Comics Unlimited since 2007 (Colton, 2007); DC Comics (2012) has sold its comics, through various platforms, such as Amazon Kindle and IBook store since 2012; ComiXology (2014) is a digital comic platform which offers both western and Japanese publishers, as well as independent creators. As exemplified, the digital comic has been established commercially. 


\section{Development of Digital Comics}

According to Eisner (2008), comics are a valid form of reading which possesses characteristics, ranging from "image-word mix" (p.7) to "image without words" (p.24). This concept of comic remains, in spite of the different media used in production. Initially, digital comics replicated the key elements and artistic look of comic books, which included still images, text images, panel arrangement, texturing and shading techniques such as screentone. However, the digital medium possesses distinctive qualities which, in turn, makes some of its functions differ from a paper comic. One of the unique qualities is what McCloud (2000) labelled an "infinite canvas" (p. 222). In digital comics, the screen acts as a window, which provides an infinitive space for arrangement of comic panels, which can be scrollable and zoomable. Another example is 'Guided View' in Comixology (2014) comics, which allows the reader to read comics, one panel at a time (Cali, 2018). In order to read a digital comic, readers are required to scroll, swipe or click instead of flipping to turn a page. Despite the different reading manner, the reader can still read the digital comic at their own pace, in the same way that they follow a paper comic.

On the other hand, comic artists start to explore motion and other animated graphic elements, as well as sound for their comic production. The integration of comics and animation leads to so-called 'motion comics'. Some examples of these motion comics are Watchmen Motion Comic (Coller \& Huges, 2009), The Walking Dead Vol. 1 (Kirkman \& Boyd, 2012), Axe Cop - The Beginning (Rug Burn, 2012). These comics share similarity in employing camera movements and animations. However, they preserve the characteristic aspects of comics in various degrees. For example, Watchmen maintains the characteristic of a comic book, by keeping the written texts, in bubbles, while, at the same time, offers audio narration. This differs from Axe Cop - The Beginning (2012), which offers only voice-over, but empties all the narrative texts from its paper comic.

According to the examples, motion comics blur the boundary between traditional comics and animations. This, in a way, affects the reading experience, because the quality of the medium is changed, as well as the perception in reading. McLuhan stated that comics "provide very little data about any particular moment in time, or aspect in space, of an object. The viewer, or reader, is compelled to participate in completing and interpreting the few hints provided by the bounding lines" (McLuhan, 1944, p.161). Thus, he regarded comics as what he termed 'cool' media. On the other side, the term 'hot' media, like animation, turns the viewer into "a passive consumer of actions." (McLuhan, 1964, p.341). Motion comics blur McLuhan's definition of comics being 'cool' media regarding the integral characteristic of the animation medium. As a result, readers of motion comics become more passive, because images are more previsualized in animation. Moreover, time is preset in motion comics which limits the reader control of pace and time in reading. This contrasts to the traditional way of reading paper comics or still digital comics which allow the readers to read at their own pace. The overuse of animation in comics can also inhibit reader control and force the reader to be an observer (Bigerel, 2009).

How can comic artists make a balance between giving their readers a unique experience of digital comics while still maintaining reader control? This article explored other possibilities for digital comics. As a case study, Protanopia (2017) was analyzed as an alternative model for a future digital comic production.

\section{Protanopia (2017)}

Protanopia is an interactive digital comic for the iPad and the iPhone, created by Bergs (2017a). It can be downloaded from the App Store. The comic application consists of 12 pages. The comic combines both three dimensional (3D) and two dimensional (2D) animation elements in a real-time game engine. 


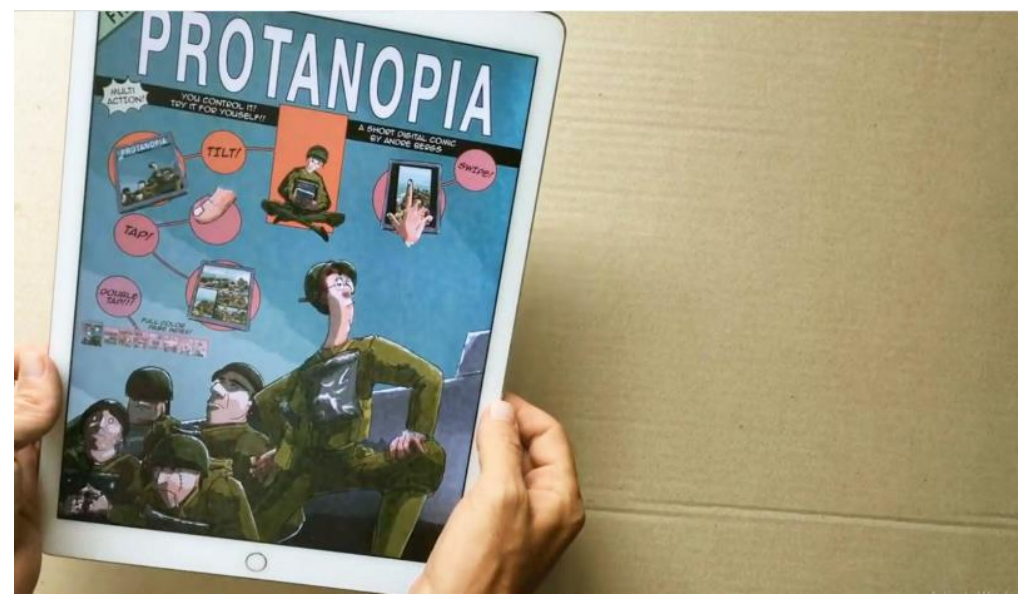

Figure 1: Protanopia Comic (Bergs, 2017a).

Set on the Normandy landing of June 6, 1944, during World War II, Protanopia is an ironical story about a soldier's strategy for the Allied invasion of Normandy. The story focuses on an idea about cognitive tunneling, which caused an inattentive blindness. The main character, Popo, claimed that a human mind tends to focus on a task and will reject other elements or information, that contrast too much with the given task. He believed that, while everybody is camouflaged, he would become invisible with his extreme jester makeup. His comrades bought the idea, but things did not go as planned. In the end, the reader sees the Axis gunman, disguised with two French braids and a girl's dress, joyfully shouting in victory to his comrades. The story reveals that the German also adopted the same strategy.

Bergs presents this dark-humor story through stylized full-color illustrations. One of the images also demonstrates a strong relationship with real captured moment from World War II.
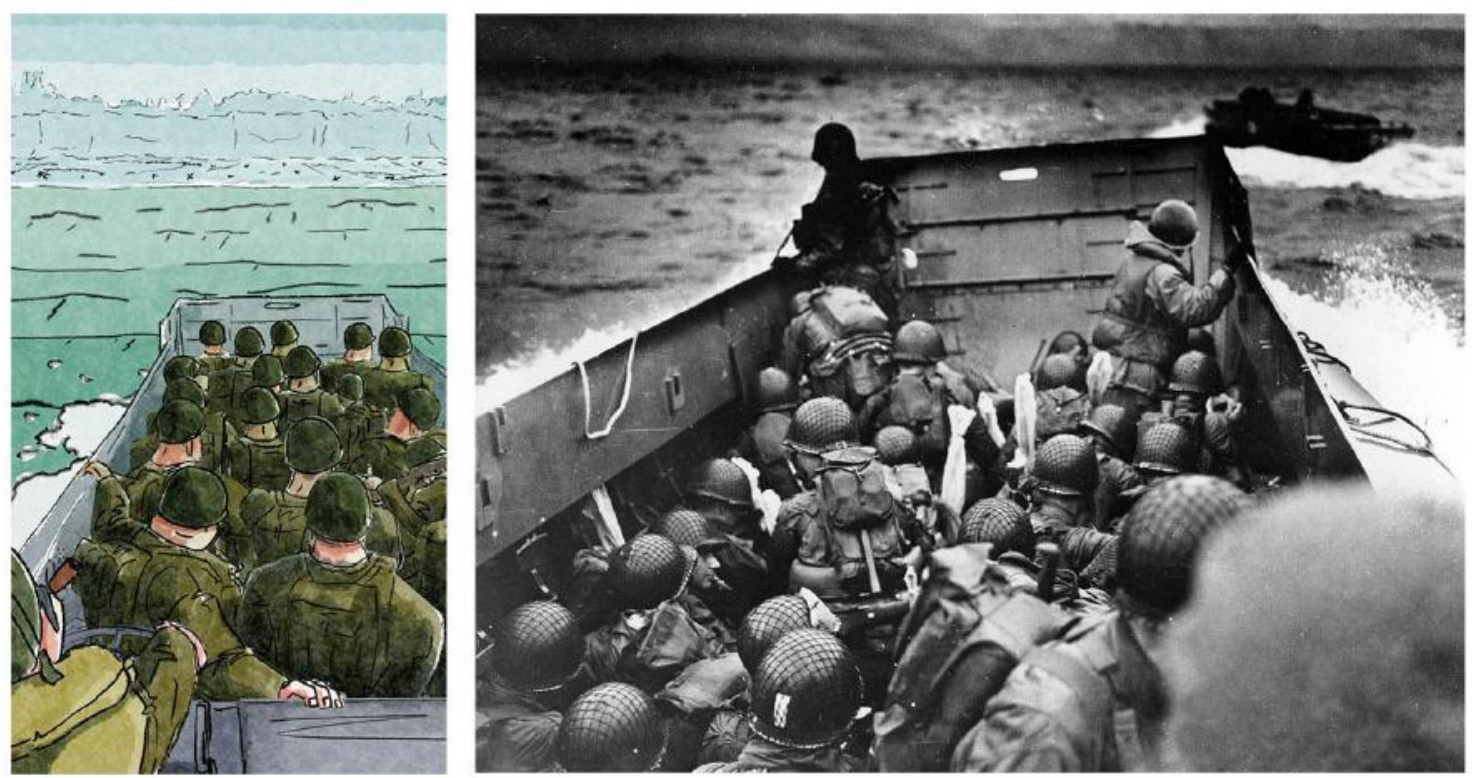

Figure 2: Left) An Image from Protanopia (Bergs, 2017a).

Figure 3: (Right) A photograph of A U.S. Coast Guard landing barge approaches the shore at Normandy, France, on, June 6, 1944 (U.S. Coast Guard, 1944).

Protanopia has multiple functions as a digital comic. With one click, readers can read the interactive comic, either a whole page, as they would view a paper comic, or read it one panel at a time. This function is similar to 
'Guided View' from Comixology (2014). It is one of the qualities of digital comics, which helps the readers absorb more information in each comic panel. Additionally, Protanopia offers reader control of viewing angles to some level according to the way the readers hold their phone or tablet. The use of reading devices such as iPad and mobile phones requires physical interaction during the process of reading, such as tapping and swiping. According to Hague (2014), this relationship between comics and the sense of touch is emphasized through touchscreen and haptic feedback, which are new elements of physical cues in digital comics. Besides tapping and swiping, tilting the mobile screen-based reading device is another physical interaction in the process of reading, that the digital comic offers. The viewing control and its consequence of the interaction, between the reader and reading material, distinguish Protanopia from other digital comics. This also gives unique and playful reading experiences to its reader.

Bergs also emphasizes the importance of reader control over their progression through narratives. According to Daniel Goodbrey (2015), artists such as Mark Waid, Yves Bigerel and Guillermo del Toro stressed reader control as one of the essential elements in making a digital comic work as a comic. Despite the same concern, Bergs' approach challenged a perceived notion of motion comics, discussed by the comic artists, that the motion comics inhibit reader control. Animation has been questioned as a key feature to constitute a digital comic. However, in Protanopia, animation was used in almost every single panel, but in a supportive way to the narrative. Bergs employed mostly looped animation in his comic for character movements, as well as for effects animation, such as water or a rocking boat. Although the animation was preset, it was in an infinite loop. On that account, the time given to its viewers became infinite. This allowed the readers to read the motion comic at their own pace. Moreover, there were three panels from the total of 32 panels, in which the motion was so subtle that the readers hardly recognized it. One of them was when the main character was about to propose his idea, while the other two panels contained the story climax. The use of subtle motions and looped animation demonstrated how Bergs captured his readers' attention, while still allowing them to focus on the story. In order to further highlight the comic features, Bergs maintained speech bubbles in his comic and emptied all sound from this project. In an interview with Justin Cone, he noted that "...in a movie, music dictates or supports the pacing, tempo and tension arcs so strongly, and for a comic to be a comic and not a movie you have to let the reader decide his or her own pace" (Bergs, 2017b).

As a digital comic application, Protanopia involved technological aspects in both the process of making and the method of publishing the application. To make the comic, Bergs employed a model of 3D animation production which included the three stages: pre-production, production and post-production. In pre-production, story ideas were organized through a script, which would be visualized in storyboarding stage. Alias Maya software was used to generate three-dimensional objects and scenes for production. Once characters and props were staged in a layout, as visualized in the storyboard, the scene was rendered. After that, the artist drew over the rendered 3D images to create a 2D look. Drawing method was used intensively in this computer-generated comic, not only for visualizing the story in the storyboarding stage, but also for creating the $2 \mathrm{D}$ images. The $2 \mathrm{D}$ drawn-images were later projected onto the 3D models. This stage is called projection mapping. Once the loop animation was created, the artist imported the file into Unity for the post production. At this stage, the artist created comic panels and scripts, then published the final work as a program. The following diagram [Figure 4] shows the production of the digital comic. 

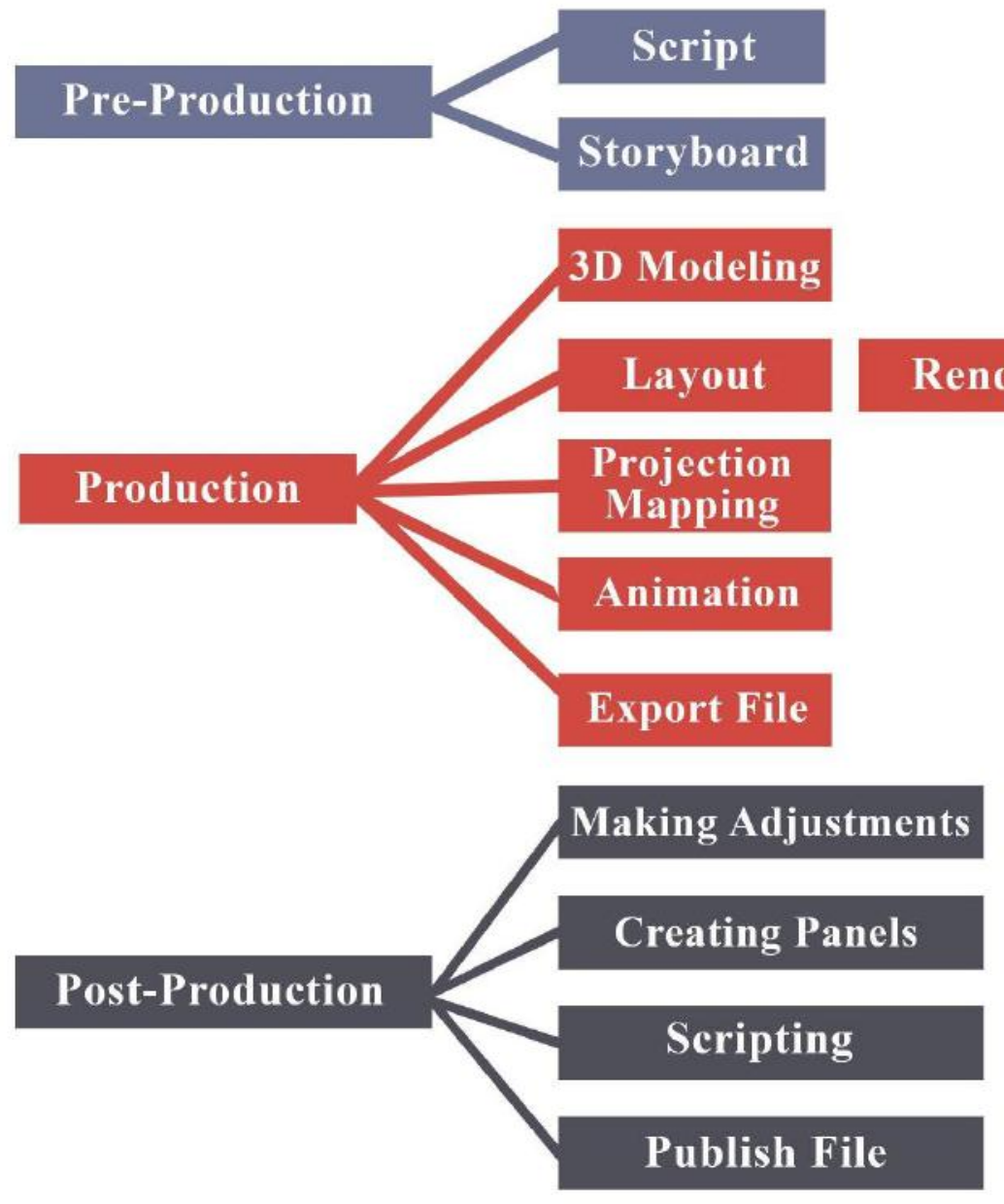

Upload

Software used in the comic production:

Adobe Photoshop Autodesk Maya Unity

Figure 4: Flow diagram for making Protanopia

Bergs noted that he spent most time to develop the overall concept. However, the most time spent on the actual work was evenly divided between the drawing, the animating and the projection mapping. These three stages occupied up to eighty percent of all the work (A. Bergs, personal communication, April 4, 2019). The process of making Protanopia inferred that drawing was still a crucial stage in digital comic-making no matter how much computer techniques were involved in the production. This confirms that the traditional approach was not discarded, it was instead implemented for comic production in this digital era.

\section{Conclusion and Future Direction}

Protanopia gained attention from both artists and media since it was released. Although the limitation of this study was to calculate digital comic sales volume, Bergs' colleague, T. Chunhachai (personal communication, February 14, 2019), revealed that the digital comic sales volume was modest compared with that of other established publishers. Since Protanopia, Bergs formed Plastiek! with Chunhachai, a Thai animator, to create more digital comics with a similar technique. As a result, their recent digital comic - RRR (Plastiek!, 2018) has been released. However, complexity and time-consuming in the work processes decelerates their publishing rate. Since 2018, the company has received some supports from an established digital technology provider Wacom Company (T. Chunhachai, personal communication, February 14, 2019). 
Despite complexity in comic production, there is a possibility that similar kinds of interactive 3D comics will grow. Not only the trend of the interactive three-dimensional image is new, but the 3D technology becomes more accessible for social media. The latest update of Facebook 3D Photo in April 2019 allows its users to view their photos in three dimensional space and the users are able to control the viewing angle to a certain level. Following this, content creators and artists, who are not skilled in software, such as Unity or Maya, can also create a 3D image with simpler graphic design software, like Adobe Photoshop. The complex, technological work process in projecting the image in a 3D space will be automated via this Facebook function. Therefore, artists can save cost and time in production. One of the downsides is that this restricts both creators and readers to the Facebook site. Moreover, when it comes to commercial aspects, the social-networking site functions differently from online stores, where people can buy things and download them directly. However, it can be used as a platform to promote works and make an artist known to others. If that is the first step before further making business, this can be a time for comic artists to capitalize on digital technology in addition to existing online platforms.

\section{References}

Bergs, A. (2017a, October 13). Protanopia. Retrieved from http://andrebergs.com/protanopia/index.html.

Bergs, A. (2017b, October 10). An Interview with Justin Cone in: Crafting a digital comic: Q\&A with André Bergs. Retrieved from http://motionographer.com/2017/10/10/crafting-a-digital-comic-qa-with-andre-bergs/.

Bigerel, Y. (2009, February 6). About Digital Comic. Retrieved from https://www.deviantart.com/balak01/art/about-DIGITAL-COMICS-111966969.

Cali, D. (2018, July 15). Digital Comics vs Print: Dawn of the Digital Age. Retrieved from https://consumereviewrepeat.com/2018/07/15/digital-comics-vs-print-dawn-of-the-digital-age/.

Coller, W. (Producer), \& Hughes, J. (Director). (2009). Watchmen Motion Comic [Motion Picture]. United States: Warner Bros.

Colton, D. (2007, November 12). Marvel Comics Shows Its Marvelous Colors in Online Archive. USA Today. Retrieved from https://usatoday30.usatoday.com/life/books/news/2007-11-12-comics-online-main_N.htm.

ComiXology. (2014, November 8). Retrieved from https://www.comixology.com/new-to comixology?tid=W140710001\&utm_source=cmx_hompage\&utm _medium=quick_link\&utm_campaign=

W140710001_new_to_comixology.

DC Comics (2012, November 7). DC Entertainment Digital Comic Books Now Available on Kindle Store, iBookStore and Nook Store. Retrieved from https://www.dccomics.com/blog/2012/11/07/dc-entertainmentdigital-comic-books-now-available-on-kindle-store-ibookstore-and.

Eisner, W. (2008). Comics and Sequential Art: Principles and Practices from the Legendary. New York, NY: Norton \& Company.

Goodbrey, M, D. (2015). Distortions in Spacetime: Emergent Narrative Practices in Comics' Transition from Print to Screen. In: R Pearson \& A.N. Smith (Eds.), Storytelling in the Media Convergence Age (pp. 54-73). London, UK: Palgrave Macmillan.

Hague, I. (2014). Comics and the Senses: A Multisensory Approach to Comics and Graphic Novels. New York, NY: Routledge.

Jensen, T. (2018, May 2). The History of Computer Art in Comics. Retrieved from https://www.geek.com/comics/the-history-of-computer-art-in-comics-1729168/.

Kirkman, R. (Producer), \& Boyd, D. (Director). (2012). The Walking Dead Vol. 1 [Motion Picture]. United States: AMC Networks.

McCloud, S. (2000). Reinventing Comics. New York, NY: Paradox Press.

McLuhan, M. (1944). Understanding Media: The Extensions of Man. Cambridge, MA: The MIT Press.

McLuhan, M. (1964). Television: The Timid Giant. In T.W. Gordon (Ed.), Understanding Media: The Extensions of Man (pp.332-347). London, UK: Routledge \& Kegan Paul.

Miranda, E. (2016, November 29). Digital vs. Print Comics. Retrieved from https://sundial.csun.edu/2016/11/digital-vs-print-comics/. 
Nagata, K. (2017, August 2). As Manga Goes Digital via Smartphone Apps, Do Paper Comics Still Have a Place?. The Japan Times. Retrieved from https://www.japantimes.co.jp/news/2017/08/02/business/manga-goesdigital-via-smartphone-apps-paper-comics-still-place/\#.XMRedrczaUk.

Plastiek!. (2008, July 4). RRR. Retrieved from https://plastiek.com/RRR/RRR.html.

Rug Burn. (2012, December 7). Axe Cop - The Beginning. [Video file]. Retrieved from https://www.youtube.com/watch?v=YHGfSBr2FrY.

U.S. Coast Guard. (1944). A photograph of A U.S. Coast Guard landing barge approaches the shore at Normandy, France, on, June 6, 1944 [Online Image]. Retrieved from https://www.stripes.com/news/5-facts-youmay-not-know-about-the-normandy-invasion-1.285851.

Ziming, L. (2005, December 1). Reading Behavior in the Digital Environment: Changes in Reading Behavior over the Past Ten Years [PDF file]. Retrieved from https://pdfs.semanticscholar.org/2dfd/8e98a271cc7d92bde32 d216f254c8800e205.pdf. 